\title{
Molecular phylogenetic analysis of genera in the family Plakobranchidae (Mollusca: Opisthobranchia: Sacoglossa)
}

\author{
Anna L. Bass ${ }^{1}$ and Stephen A. Karl ${ }^{2}$ \\ Department of Biology, SCA 110, University of South Florida, 4202 E. Fowler Ave., Tampa, Florida 33620 USA \\ ${ }^{1}$ To whom correspondence should be addressed: Email: abass@mail.usf.edu \\ ${ }^{2}$ Current address: The Hawai'i Institute of Marine Biology, University of Hawai'i, Manoa, \\ P.O. Box 1346, Kane'ohe, Hawai'i, 96744, Email: skarl@hawaii.edu
}

\begin{abstract}
Genera in the largest family of the suborder Sacoglossa (Mollusca; Opisthobranchia), the Plakobranchidae Gray, 1840, have been systematically revised numerous times since the 1800 s. Several authors have questioned the validity and inter-relationships of the genera Tridachia Moerch, 1863, Tridachiella MacFarland, 1924, Elysiella Bergh, 1872, Pattyclaya Marcus, 1982, Elysia Risso, 1818, and Thuridilla Bergh, 1872. For many other groups, molecular data have proven fruitful in determining the systematic relationships of organisms for which few suitable morphological characters are available. Using DNA sequence data from one nuclear (Histone 3) and two mitochondrial genes (Cytochrome Oxidase subunit I and large ribosomal subunit), we infer the phylogenetic relationships among five of the seven recently recognized genera within the Plakobranchidae. These data question the monophyly of the genus Elysia and suggest that further divisions within the genus may be necessary. Additionally, it appears that the family Boselliidae Marcus, 1982 may be, at least, paraphyletic since one member of the genus Bosellia Trinchese, 1891, clusters within the family Plakobranchidae.
\end{abstract}

Key words: Opisthobranchia, Sacoglossa, Plakobranchidae, molecular phylogenetics

\section{INTRODUCTION}

Jensen (1996) and Mikkelsen (1998) using a cladistic analysis of morphological characters assessed the higher-level relationships within the suborder Sacoglossa. These analyses indicated that Limapontioidea Gray, 1847 is a sister group to the superfamily Plakobranchoidea Rang, 1829, which contains the family Plakobranchidae Gray, 1840. The family Limapontiidae Gray, 1847 is currently recognized as a member of the superfamily Limapontioidea (Jensen 1996; Mikkelsen 1998).

The family Plakobranchidae, with anywhere from 90-100 species, is the largest in the order Sacoglossa (Jensen 1997a, b). Since the 1800s members of this family have been variously divided into as few as nine and as many as 14 genera (Jensen 1992). Many of these revisions resulted in the designation of monotypic genera and families (e.g., Plakobranchus, is the sole member of the Plakobranchidae sensu Marcus 1982). Based on anatomical descriptions of a greater number of specimens and the identification of characters associated with internal organs, Jensen (1992) argued for the retention of five genera, but not the monotypic family, Plakobranchidae. Unfortunately, specimens of the monotypic genera Tridachia and Tridachiella were not included in Jensen's study and no conclusions as to their status could be drawn. Based on an assessment of 12 morphological characters measured in representatives of all seven genera, Gosliner (1995) demonstrated that Thuridillla and Plakobranchus cluster together. The remaining five genera, however, formed a polyphyletic clade (Figure 1). Based on these observations, Gosliner proposed retention of the genera Thuridilla, and Plakobranchus but synonymizing the remaining taxa as Elysia. Since these studies, no further attempts to determine the phylogenetic relationships of Plakobranchidae genera or species have been made.

The historical volatility of the taxonomy of the Plakobranchidae is not particularly surprising. Overall, members of the family appear to be extremely conservative in terms of variation in body form. As for others in the Sacoglossa, and mollusks in general, members of the family possess few morphological characters capable of reliably inferring evolutionary relationships. Many of the named species are based on the inspection of a single individual and often rely on malleable characters such as coloration and radular tooth morphology. Coloration or patterns of color are given in species descriptions, but only from live specimens as preservatives destroy all color except for black pigments. In addition, diet may also affect 


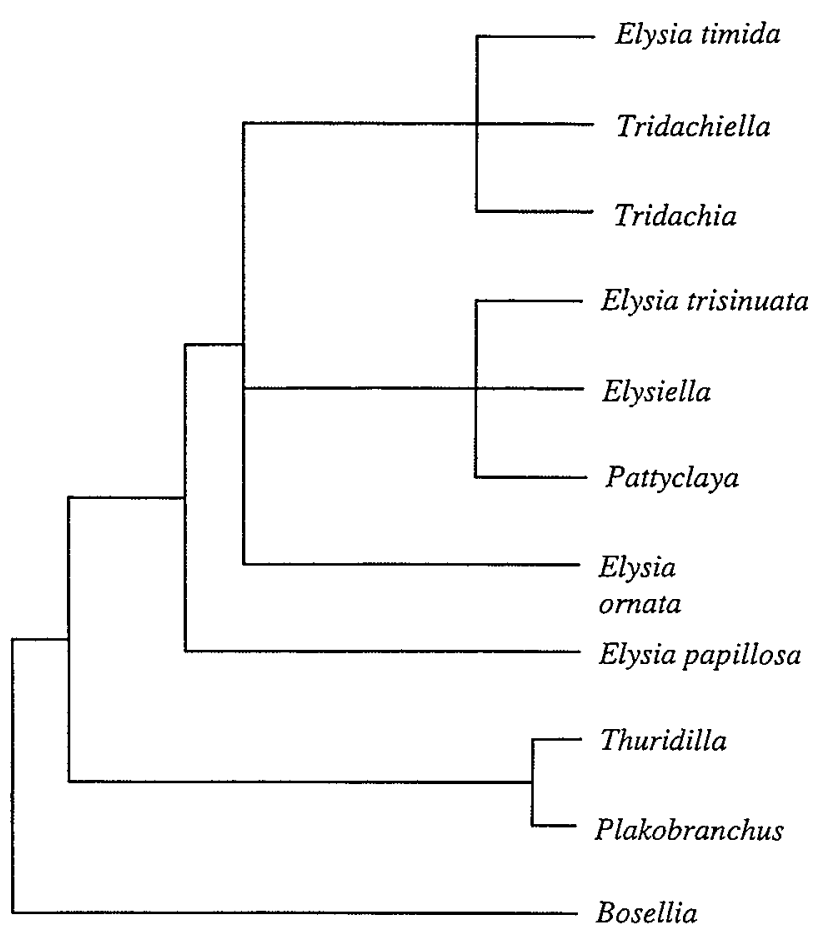

Figure 1 Systematic relationships among genera of Plakobranchidae as proposed by Gosliner (1995).

color (Marcus 1980) thus reducing its reliability for systematic purposes. Other common characters are the presence of papillae on head, rhinophores and parapodia. Radular teeth characteristics are included in a majority of descriptions, but also may be unreliable for species identification since tooth shape can be directly affected by diet (Jensen 1993). Populations of many of the species experience large temporal fluctuations in density (e.g., E. chlorotica; Bleakney, 1996), however, there has been little to no assessment of intra-specific or inter-seasonal variation in taxonomic characters. Some of the most useful characters are subtle differences of internal organs found through detailed anatomic examination (Jensen 1992). The shape of the pharynx, shape of the reproductive systems, and the presence or absence of a pharyngeal pouch might be the best way to differentiate between species. Accurate quantification of internal softbody characteristics, however, is exceptionally time consuming and requires a significant investment in training. It may be advantageous, therefore, also to develop complementary approaches to aid in the reconstruction of sacoglossan relationships.

Here, we present a systematic analysis of the Plakobranchidae based on nuclear and mitochondrial DNA sequence data of five of the seven genera presented in Gosliner (1995). Specifically, we test the previously proposed systematic relationship of the genera, the monophyly of the genus Elysia, and the relationship of the Plakobranchidae to the family Boselliidae
Marcus 1982. Two members of the family Limapontiidae are included as outgroups. Two genes from mitochondrial DNA genome, cytochrome oxidase subunit I (COI) and large ribosomal subunit (16S) were targeted due to their reported use in the resolution of family to genus level divergences (Folmer et al. 1994; Medina and Walsh 2000; Simon et al. 1994). We included data from the nuclear gene Histone 3 to examine its utility in resolving deeper level divergences observed after the collection of the mitochondrial DNA data. H3 has been used successfully to determine deep level taxonomic relationships in gastropods (Colgan et al. 2000) and insects (Danforth et al. 2005).

\section{MATERIALS AND METHODS}

Individuals from five of the seven genera in Plakobranchidae, two species from Bosellidae and two species from a single genus in the Limapontiidae (Table 1) were collected, anesthetized with $\mathrm{MgCl}_{2}$ and stored in $95 \% \mathrm{EtOH}$. Samples were collected between 2000 and 2003. Two population samples were collected for Elysia papillosa and Tridachia crispata. Total cell DNA was isolated from a small portion of the anterior end of the animal subjected to a non-boiling chelex method (Walsh et al. 1991) and used in subsequent polymerase chain reaction (PCR) amplifications of three genes. All treated samples were diluted with 1X TE (10 mM Tris, $1 \mathrm{mM}$ EDTA; pH 7.5) and stored at $-20^{\circ} \mathrm{C}$.

Segments of two mitochondrial genes ( $700 \mathrm{bp}$ of cytochrome $c$ oxidase subunit I [COI] and $\sim 450 \mathrm{bp}$ of the large subunit RNA [16S]) and one nuclear gene ( 380 bp of Histone 3 [H3]) were PCR amplified with primer pairs, respectively, LCO1490 5'-GGT CAA CAA ATC ATA AAG ATA TTG G-3' and HCO2198 5'-TAA ACT TCA GGG TGA CCA AAA AAT CA-3' (Folmer et al. 1994), 16Ssar 5'-CGC CTG TTT ATC AAA AAC AT-3' and 16sa 5'-CTC CGG TTT GAA CTC AGA TC-3' (Kessing et al. 1989), and H3F 5'-ATG GCT CGT ACC AAG CAG ACV GC-3' and H3R 5'-ATA TCC TTR GGC ATR ATR GTG AC-3' (Colgan et al. 2000). Amplification reactions (25 or $50 \mathrm{~mL}$ ) consisted of $1 X$ buffer (Enzypol LTD., Denver, CO), 1.5 units of Enzypol Plus 2000 polymerase (Enzypol LTD., Denver, CO), $0.2 \mathrm{mM}$ each dNTPs, $3.0 \mathrm{mM} \mathrm{MgCl}$ (COI and 16S) or $1.5 \mathrm{mM} \mathrm{MgCl}_{2}(\mathrm{H} 3), 0.5 \mathrm{mM}$ of each primer, 1.0 $\mathrm{M}$ Betaine, $0.12 \mathrm{mg} / \mathrm{mL}$ of bovine serum albumen, and $2.0-4.0 \mathrm{~mL}$ of template. The cycling conditions for the COI and $16 \mathrm{~S}$ primers consisted of $1 \mathrm{~min}$. at $95^{\circ} \mathrm{C}$ followed by $35-45$ cycles of $30 \mathrm{sec}$. at $95^{\circ} \mathrm{C}, 45$ sec. at $48^{\circ} \mathrm{C}$, and $1 \mathrm{~min}$. at $72^{\circ} \mathrm{C}$ with a final extension of $3 \mathrm{~min}$. at $72^{\circ} \mathrm{C}$. Cycling conditions for the $\mathrm{H} 3$ primers consisted of 1 cycle of $4 \mathrm{~min}$. at $95^{\circ} \mathrm{C}, 1 \mathrm{~min}$. at $50^{\circ} \mathrm{C}$, and $1 \mathrm{~min}$. at $72^{\circ} \mathrm{C}$, followed 
Table 1 Material examined in the analysis including family and species designation, brief locality description, number of sequences or individuals used and type of genetic data available for the analysis.

\begin{tabular}{llll}
\hline Taxa & Locality & $\#$ & Gene \\
\hline $\begin{array}{c}\text { Bosellidae } \\
\text { Bosellia marcusi } \\
\text { Bosellia mimetica }\end{array}$ & Bahamas & & \\
Limapontiidae & Bahamas & 1 & COI, 16S, H3 \\
Costasiella kuroshimae & & 3 & COI, 16S, H3 \\
Costasiella ocellifera & Guam & & \\
Plakobranchidae & Bahamas & 1 & COI, 16S, H3 \\
Elysia papillosa & & 1 & COI, 16S, H3 \\
Elysia ornata & Bahamas, Florida Keys & 4,4 & COI, 16S, H3 \\
Elysia timida & Philippines & 1 & COI, 16S, H3 \\
Elysiella pusilla & Florida Keys & 2 & COI, 16S, H3 \\
Plakobranchus ocellatus & Hawaii & 2 & COI, 16S \\
Thuridilla carlsoni & Guam & 1 & COI, 16S, H3 \\
Thuridilla undula & Hawaii & 2 & COI, 16S, H3 \\
Tridachia crispata & Philippines & 1 & COI, 16S, H3 \\
\hline
\end{tabular}

1 Majority rule consensus sequences for Belize and Florida Keys are based on one and three individuals for $16 \mathrm{~S}$ and six and ten individuals for $\mathrm{CO} 1$, respectively.

2 Histone 3 sequence data from the Florida population only.

by 35 cycles of $45 \mathrm{sec}$. at $95^{\circ} \mathrm{C}, 30 \mathrm{sec}$. at $52^{\circ} \mathrm{C}$, and $45 \mathrm{sec}$. at $72^{\circ} \mathrm{C}$ and a final extension of $3 \mathrm{~min}$. at $72^{\circ} \mathrm{C}$. A template free reaction was included for the detection of contamination.

Amplicons were purified using sterile nanopure water and 30,000 MW Millipore filters (Millipore Inc., Bedford, MA). The mass of the amplicons was determined by comparing ethidium bromide staining intensity of $2.0-5.0 \mathrm{~mL}$ of each purified reaction relative to a standard mass DNA ladder (Invitrogen Life Technologies, Carlsbad, CA). Cycle sequencing reactions (Amersham ET-Terminator Kit, Amersham Biosciences Corp., Biscataway, NJ) were conducted with approximately $100 \mathrm{ng}$ of purified PCR product according to manufacturers specifications and fluorescently labeled products were size sorted and visualized using an ABI 310 Genetic Analyzer (Applied Biosystems, Inc., Foster City, CA). The sequences from both strands of the amplicon were compared and edited (when needed) using Sequencher (v4.1; Gene Codes Corp., Ann Arbor, MI). The $16 \mathrm{~S}$ gene region fragments were aligned using Clustal W (Higgins et al. 1996) and the resulting alignment was verified by eye and to identify hyper-variable regions where no one alignment appeared superior to another. The open reading frame for the $\mathrm{COI}$ and $\mathrm{H} 3$ genes were used to aid in proper alignment.

Maximum likelihood analysis as implemented in PAUP* (v4.0b10; Swofford 1998) was conducted on a best-fit model (TVM $+\mathrm{I}+\mathrm{G})$ of all the data as selected by Modeltest with Akaike information criteria (v3.06; Posada and Crandall 1998). Heuristic tree searches were conducted on ten trees generated from a stepwise addition (with random taxon addition) and tree-bisection-reconnection (TBR) branch swapping. In all analyses, gaps were treated as missing data. To evaluate the relative divergence levels among taxa, the best-fit model of evolution as selected in Modeltest using Akaike information criteria (v3.06; Posada and Crandall 1998) was determined for all genes combined excluding putative $3^{\text {rd }}$ positions of the COI fragment. Putative third positions of the COI fragment were excluded after the indication of saturation of both transitions and transversions for all species as evidenced by a nonlinear relationship in a plot of the number of substitutions versus uncorrected pairwise percent sequence difference. The two intra-specific level samples were treated in the same manner to facilitate overall comparisons. Estimates of divergence were generated using a maximum likelihood estimator with PAUP*. Average divergence estimates were compared using a Student's t-test (Sokal and Rohlf 1995) to assess sequence divergence at various taxonomic ranks.

A Bayesian framework was used to determine clade support among the species of interest (Mr. Bayes v3.0b4; Huelsenbeck and Ronquist 2001). The data was divided into seven partitions: putative $1^{\text {st }}$, $2^{\text {nd }}$ and $3^{\text {rd }}$ codon positions of COI, putative $1^{\text {st }}, 2^{\text {nd }}$, and $3^{\text {rd }}$ codon positions of $\mathrm{H} 3$, and all positions of 16S. Under this partition framework, 4,000,000 generations were run and sampled every 1,000 generations. Model parameters, proportion of invariant sites, gamma distribution and nucleotide substitution rates, were estimated independently for each partition using Mr. Bayes default values of four chains and 0.2 for the chain temperature parameter. Four chains starting from random trees were run to determine if independent chains had converged and on average a "burnin" of 2,000 was used to determine posterior probability values.

Alternative tree topology hypotheses were tested 
using a one-tailed Kishino-Hasegawa (K-H) maximum likelihood test as implemented in PAUP*. To test the hypothesis that Bosellidae is a monophyletic family, constrained (Bosellia mimetica + Bosellia marcusi) and unconstrained maximum likelihood trees were generated and compared.

\section{RESULTS}

At total of 1,417 nucleotides of sequence data collected from a total of 25 individuals from 12 species was used in the analysis (Table 1). For two species, Elysia papillosa and Tridachia crispata, majority rule consensus of the sequence data from multiple (2-10) individuals from two locations were included. Both 165 and CO1 sequences were collated from four individuals from the Bahamas and Florida Keys populations of Elysia papillosa and the majority rule consensus sequences were used in the analyses. For Tridachia crispata the $16 \mathrm{~S}$ majority rule consensus sequences are based on one and three individuals from the Florida Keys and Belize, respectively. The $\mathrm{CO} 1$ majority rule consensus sequences are based on ten and six individuals from the Florida Keys and Belize, respectively. All three genes were assayed from at least one individual from 13 species but sequence data was obtained for only two genes (COI and 16S) from Elysiella pusilla due to technical difficulties in amplifying $\mathrm{H} 3$ from this species (Table 1). A small region of the $16 \mathrm{~S}$ gene (i.e., 50 nucleotides) appeared to be highly variable and concerns about site homology resulted in it being excluded from the analysis.

The topology of the Bayesian and ML trees were identical except that in the Bayesian analysis Elysia ornata was grouped with the Elysia papillosa clade (Figure 2) as opposed to at the base of the clade containing the remaining plakobranchids as was the case for the ML analysis. A K-H test indicated that the ML and Bayesian trees were not significantly different $(\mathrm{K}-\mathrm{H}=0.878)$ and clade credibility values for the Bayesian analysis generally were large. Similarly, the hypothesis of a monophyletic Boselliidae resulted in a less likely tree than a

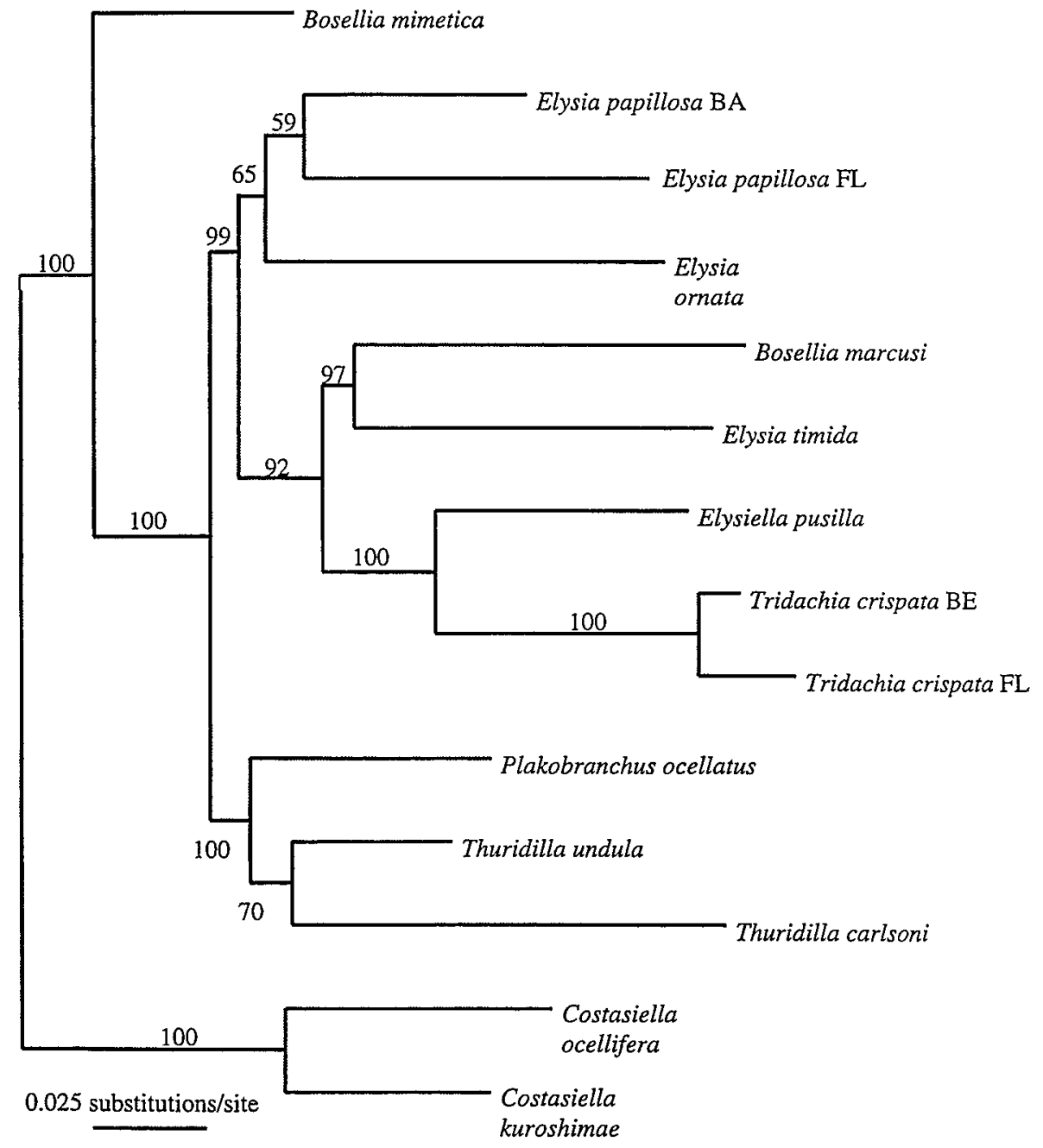

Figure 2 Maximum likelihood tree of the relationships among five of the seven genera used in Gosliner (1995), and members of the families Bosellidae and Limapontiidae. BE = Belize, BA = Bahamas and FL = Florida Keys. Costasiella species were used to root the tree. Bayesian posterior node probability values were estimated after an average burn-in of 2000 . 
Table 2 Estimates of sequence divergence based on combined data. Putative third positions in the COI fragment were excluded due to saturation. Divergence was estimated under a maximum likelihood framework with model $(T V M+I+G)$ determined using ModelTest and AIC (Posada and Crandall 1998) and PAUP* (Swofford 1998).

\begin{tabular}{lccl}
\hline Taxonomic Level & $( \pm$ SD) & Range & Expected Magnitude \\
\hline Intra-specific $^{1}$ & $0.058 \pm 0.049$ & $0.024-0.093$ & None - Small \\
Inter-specific Congeneric $^{\text {Inter-generic Confamilial }}$ & $0.160 \pm 0.027$ & $0.124-0.196$ & Small - Moderate \\
Inter-familial & $0.150 \pm 0.036$ & $0.094-0.209$ & Moderate - Large \\
\hline
\end{tabular}

${ }^{1}$ Estimates are based on more than two individuals from more than one population of Elysia papillosa and Tridachia crispata.

topology where Bosellia marcusi was clustered within the Plakobranchidae clade $(\mathrm{K}-\mathrm{H}=0.003, \mathrm{p}<$ 0.05 ).

An analysis of the maximum likelihood distances for various hierarchical taxonomic classifications did not yield a strong correlation to taxonomic level (Table 2). Student's t-tests indicated that the there were significant differences in average divergence estimates in two of four comparisons. The average divergences between intra- and inter-specific congeneric categories were significantly different $(p$ $=0.013$ ) as were the averages between inter-generic confamilial and inter-familial categories $(p=0.001)$. The remaining categories, inter-specific congeneric versus inter-generic confamilial and inter-specific congeneric versus inter-familial, were not significantly different $(\mathrm{p}=0.615$ and $\mathrm{p}=0.180$, respectively).

\section{DISCUSSION}

One of the fundamental strengths of our approach is that DNA sequence data often can reveal significantly more variation than detailed internal morphological analyses and therefore our conclusions are based on a larger suite of variable characters taken from several members of each targeted taxa. The ability to include more than one individual of a taxa allows us to begin to address the degree of intra-group variation as well as sister group associations. Historically, descriptions of members of the family Plakobranchidae have been limited to single individuals with no comparisons among material from multiple locations (as noted in Jensen 1992). Both here, and as part of a larger study of variation within the family Plakobranchidae, we have sampled several individuals within putative single species and found for intraspecific comparisons both large $(d=$ $9.2 \%$; Elysia papillosa) and small degrees of variation ( $d=2.3 \%$; Tridachia crispata) among populations of named species. Estimates of intra-specific variation are derived only for E. papillosa and T. crispata because these are the species for which we have more than two samples from more than one location. The significant amount of genetic differentiation found between $E$. papillosa in the Bahamas and the Florida Keys indicates that these clearly are not conspecifics. The assessment of morphological differences among taxa is without question essential. Nonetheless, the inclusion of molecular approaches can provide a wealth of data for systematic analysis as well as a divining rod for further investigations of interesting morphological characteristics. In this case, now that clear evolutionary divergence has been established through genetic analyses, investigation of the morphology of this species is likely to reveal previously overlooked physical differences.

\section{Paraphyly and systematic relationships}

This study supports the conclusions of Gosliner (1995) in reference to the question of paraphyly within the family Plakobranchidae since Elysia is clearly paraphyletic in our analysis. Furthermore, considering just the topology of the tree, our results are consistent with Gosliner's proposal to subsume Elysiella and Tridachia into Elysia. Even so, we do not support this proposal but instead believe that further generic designations within Elysia are appropriate. As indicated previously, there is a large degree of genetic divergence seen throughout the Plakobranchidae. The degree of divergence among the taxa in the Elysia/Bosellia/Tridachial Elysiella clade (Figure 2) is considerable and equivalent to that seen among other genera (i.e., Plakobranchus and Thuridilla). Consider just the degree of genetic divergence seen among these taxa. If we were to support subsuming Tridachia and Elysiella into Elysia we should be equally compelled to subsume other legitimate generic (e.g., Plakobranchus and Thuridilla) as well as inter-familial (e.g., Bosellia marcusi) level designations due to similar topological arrangements and divergence levels. Alternatively, if we accept Plakobranchus and Thuridilla as valid genera then we also should accept generic level status for Tridachia and Elysiella. Further generic and species level designations within Elysia would also be necessary. This is consistent with Jensen's (1997a) proposal that the large number of described species in Elysia and the dearth of reliable taxonomic characters for these 
organisms warrant further divisions within Elysia. We propose to leave Tridachia and Elysiella as valid genera, and sister taxa, however, until a more thorough sampling and taxon analysis of Elysia can be completed. Bosellia marcusi should either be subsumed into genus Elysia or reassigned at the generic level thus resolving the paraphyly of both Elysia and Bosellia. The Elysia ornata + E. papillosa clade satisfies the condition of monophyly at similar divergence levels and can be left unchanged. We emphasize, however, that any decision at this time is preliminary and final revisions require a more comprehensive survey of members of the Plakobranchidae.

Our data confirm previous indications by Jensen (1996) and Mikkelson (1998) that the species Bosellia mimetica is closely related to Plakobranchidae. The family Bosellidae was erected because of the lack of parapodia and a different chromosome number (for Bosellia mimetica) relative to other plakobranchids $(\mathrm{n}=7$ vs $\mathrm{n}=17$; Marcus 1982; Mancini and Sordi 1965). Thompson and Jaklin (1988) also report that a chitinous penial stylet, "other features of the reproductive system (Sanders-Esser 1984)" and the absence of parapodia differentiate Bosellia mimetica from members of the genus Elysia. Even so, they preferred to keep Bosellia within a larger more "broadly defined Elysiidae" family. Our data clearly indicate that $B$. mimetica clusters outside but adjacent to the family Plakobranchidae. The divergence between $B$. mimetica and the Plakobranchidae $(0.143 \pm 0.025)$ is less than that for $B$. mimetica to the Limapontiidae (Costasiella kuroshimae and C. ocellifera; $0.164 \pm 0.013$ ) and from the Limapontiidae to the Plakobranchidae $(0.219 \pm$ 0.027).

The placement of Bosellia marcusi within the Plakobranchidae and not with its congener was an unexpected result (Figure 2). Marcus' original description of $B$. marcusi was based on several specimens collected in Florida (Marcus 1973). Subsequently, however, no further sightings of this species had been recorded until Thompson (1977) found specimens in Jamaica. While collecting in the Bahamas, we recovered a single specimen of $B$. marcusi and four specimens of $B$. mimetica from the same clump of Halimeda sp. Photographs taken of the Bahamian specimens (ALB) appear to match the original description by Marcus (1973) and both the description and drawing of Thompson (1977) (Colin Redfern, pers. comm.). The placement of B. marcusi within the plakobranchids and not with its congener in our analysis is robust as indicated by large posterior probability values at internal nodes leading to this clade. Constraining the tree to produce a monophyletic Boselliidae yields a significantly less likely tree than the unconstrained topology (i.e., Figure 2). Although B. marcusi shares characters with $B$. mimetica including eyes posterior to rhinophores and lack of parapodia, Marcus (1973) notes several differences. These include more slender radular teeth, an unpaired furrow on the right side, a true bursa copulatrix, and a short and wide penial stylet in B. marcusi (Marcus 1973). The strong affinity with Elysia timida indicates one of two possibilities; similar morphological and molecular characters due to convergence, or $B$. marcusi is incorrectly named. In reference to convergence of morphological characters, both $B$. marcusi and $E$. timida have slender radular teeth and both feed on genera of calcified green algae, either Halimeda or Acetabularia, respectively. Clearly, more specimens of $B$. marcusi are needed before a firm conclusion can be reached. Regardless, we do not believe that the final taxonomic status of $B$. marcusi is likely to change our conclusions concerning the plakobranchids.

\section{Taxonomic rank and evolutionary history}

If taxonomic rank reflects evolutionary history, then we expect a general increase in the magnitude of divergence from the intra-specific through intergeneric to the inter-familial levels (see Johns and Avise, 1998). In addition, although there likely is a range of divergence estimates within a taxonomic level, the ranges should not, in general, substantially overlap adjacent levels and this should be even less so for non-adjacent ones. For example, the upper end of the divergence range for intraspecific comparisons would not include the lower end of the inter-familial range. An absence of this pattern likely indicates problems with the divergence estimates or the assigned taxonomy. The divergence data presented here do not conform to this predicted pattern (Table 2). As mentioned previously, the magnitude of divergence seen between the Bahamas and the Florida Keys for $E$. papillosa is quite large and indicates that further taxonomic divisions are necessary for this species. This again is indicated in that the smallest intergeneric confamilial divergence estimate is nearly identical to the largest intra-specific comparison. Clearly, this level of divergence cannot simultaneously be indicative of divergence within species and between genera. Furthermore, the interspecific congeneric and inter-generic confamilial ranges completely overlap. In fact, the former is completely subsumed by the latter. More importantly, some divergence estimates between species within a genus $(0.124=d=0.196)$ are larger than those seen between families $(0.115=d=0.245$; Table 2). It could be that the taxonomic ranks are correct as currently formulated, but molecular evolutionary rates have varied across taxa or that evolutionary rates have stayed approximately constant, but taxonomic rankings are wrong or some combination of the two. We do not believe that variable evolutionary rate alone is sufficient 
explanation because highly uneven branch lengths are not seen in the tree topology (Figure 2) and both presumably too large (e.g., inter-specific congeneric comparisons) and too small (e.g., inter-generic confamilial) divergence values are seen requiring both acceleration and deceleration. Even so, given the limited taxon sampling and preliminary nature of the analysis we are unable at this time to provide a definitive answer for the discrepancy observed between the current taxonomy and the observed genetic divergence estimates.

The large molecular divergence estimates within the Plakobranchidae are consistent with Jensen's (1997a) view that the genus Elysia needs further division at both the generic and specific levels. The apparent decoupling of external morphology (i.e., current taxonomy) with genetic divergence indicates that we may be greatly underestimating the number of taxa within this family. If these findings hold, they are likely to affect multiple aspects of sacoglossan biology. Investigations relying on an understanding of the evolution of this family would presumably assume that the current taxonomy accurately reflects evolutionary history. Where the two diverge, the result would be either an over- or under-estimate of taxonomic diversity and misleading evolutionary inferences. For example, if kleptoplasty were a key innovation leading to radiation of the Sacoglossa as suggested by Wägele (2004) there should be a concomitant increase in the numbers of species with the evolution of kleptoplasty. If estimates of the taxonomic diversity in the clade of interest or in reference clades are either over- or under-estimates then potential radiation events are likely to be overlooked. Regardless, a stable taxonomy is in itself a laudable goal in this taxonomically protean group. An excellent example is the 150-year taxonomic history of ornata-like species that have variously experienced, at least three generic splits, 13 species descriptions, and seven species synonymizations (Kelaart 1858; Pease 1860; Pease 1871; Bergh 1872; Eliot 1904; Eliot 1906; Baba 1936; Baba 1957; Thompson 1973; Thompson 1977; Carlson and Hoff 1978; Marcus 1980; Heller and Thompson 1983; Jensen 1992).

Overall, the family Plakobranchidae clearly presents interesting biological and systematic issues for further investigations. The results of this study generally conform to the currently accepted relationships of the various groups. Several previously proposed revisions, however, also appear to be supported. Primarily, the genus Elysia contains a considerably amount of evolutionary diversity not currently reflected in its morphology or its taxonomy and Bosellia marcusi is likely a member of the Plakobranchidae to the exclusion of at least some of its congeners. Specific and robust inferences based on the molecular data, however, will have to wait for the results from a more complete taxon sampling effort currently underway.

\section{ACKNOWLEDGEMENTS}

We thank numerous people for collecting specimens in far reaches of the world or assisting with collections in Florida and the Bahamas. We particularly want to thank Clayton Carlson and Patty Jo Hoff for their support and collections. In addition, the following persons were instrumental to this study: Robert and Roberta Bass, Victor Bonito, Chris and Jane Bowen, Lucas Cervera, Anne Dupont, Pauline Fiene, Matt Garvey, Daniel Geiger, Ken Hayes, Kathe Jensen, Mike Miller, Jodi Nettleton, Robert Ohms, M OMalley, Cory Pittman, Victor Raphael, Luiz Rocha, Tonia Schwartz, Emily Severance and Cynthia Trowbridge. This research was supported by grants from The Conchologists of America, PADI Foundation, Unitas Malacologica, USF Department of Biology and the National Science Foundation (DEB 9806905 and DEB 0321924).

\section{REFERENCES}

Baba, K. (1936). Opisthobranchia of the Ryukyu (Okinawa) Islands. Journal of the Department of Agriculture, Kyushu Imperial University 5: 1-50.

Baba, K. (1957). The species of the genus Elysia from Japan. Publications of the Seto Marine Biological Laboratory 6: 69-75.

Bergh, R.S. (1872). Malacologische Untersuchungen. 1: 137203, pls. 17-24.

Bleakney, J.S. (1996). Sea Slugs of Atlantic Canada and the Gulf of Maine. Nimbus Publishing and The Nova Scotia Museum, Halifax, Nova Scotia.

Carlson, C.H. and Hoff, P.J. (1978). The identifiable Elysia from Guam (Elysiidae, Sacoglossa, Opisthobranchia). Micronesica 14: 89-113.

Colgan, D.J., Ponder, W.F. and Eggler, P.E. (2000). Gastropod evolutionary rates and phylogenetic relationships assessed using partial 28S rDNA and histone H3 sequences. Zoologica Scripta 29: 29-63.

Danforth, B.N., Lin C.P. and Fang, J. (2005) How do insect nuclear ribosomal genes compare to proteincoding genes in phylogenetic utility and nucleotide substitution patterns? Systematic Entomology DOI: 10.1111/J.1365-3113.2005.00305.x

Eliot, C. (1904). On some nudibranchs from East Africa and Zanzibar. Part VI. Proceedings of the Zoological Society of London 2: 268-298.

Eliot, C. (1906). On the nudibranchs of southern India and Ceylon, with special reference to the drawings by Kelaart and the collections belonging to Alder and Hancock preserved in the Hancock Museum at Newcastle-on-Tyne. Proceedings of the Zoological Society of London 1906: 639-691.

Folmer, O., Black, M., Hoeh, W., Lutz, R. and Vrijenhoek, 
R. (1994). DNA primers for amplification of mitochondrial cytochrome $c$ oxidase subunit I from diverse metazoan invertebrates. Molecular Marine Biology and Biotechnology 3: 294-299.

Gray, J.E. (1840). Synopsis of the contents of the British Museum. $42^{\text {nd }}$ ed., 1-370.

Gray, J.E. (1847). A list of the genera of Recent Mollusca, their synonyma and types. Proceedings of the Zoological Society of London 15: 129-219.

Gosliner, T.M. (1995). The genus Thuridilla (Opisthobranchia: Elysiidae) from the tropical IndoPacific, with a revision of the phylogeny and systematics of the Elysiidae. Proceedings of the California Academy of Sciences 49(1): 1-54.

Heller, J. and Thompson, T.E. (1983). Opisthobranch molluscs of the Sudanese Red Sea. Zoological Journal of the Linnaean Society 78: 317-348.

Higgins, D.G., Thompson, J.D. and Gibson, T. J. (1996). Using CLUSTAL for multiple sequence alignments. Methods in Enzymology 266: 383-402.

Huelsenbeck, J.P. and Ronquist, F. (2001). MrBayes: Bayesian inference of phylogeny. Bioinformatics 17: 754-755.

Jensen, K.R. (1992). Anatomy of some Indo-Pacific Elysiidae (Opisthobranchia: Sacoglossa (=Ascoglossa)), with a discussion of the generic division and phylogeny. Journal of Molluscan Studies 58: 257-296.

Jensen, K.R. (1993). Morphological adaptations and plasticity of radular teeth of the Sacoglossa (=Ascoglossa) (Mollusca: Opisthobranchia) in relation to their food plants. Biological Journal of the Linnaean Society 48: 135-155.

Jensen, K.R. (1996). Phylogenetic systematics and classification of the Sacoglossa (Mollusca, Gastropoda, Opisthobranchia). Philosophical Transactions of the Royal Society of London 351: 91-122.

Jensen, K.R. (1997a). Systematics, phylogeny and evolution of the Sacoglossa (Mollusca, Opisthobranchia). Vestjydsk Forlag, Denmark.

Jensen, K.R. (1997b). Sacoglossa (Mollusca, Opisthobranchia) from the Darwin Harbour area, Northern Territory, Australia. In J.R. Hanley, G. Caswell, D. Megirian and H.K. Larson (eds), Proceedings of the Six International Marine Biological Workshop. The marine flora and fauna of Darwin Harbour, Northern Territory, Australia, 1:163-186. Museums and Art Galleries of the Northern Territory and the Australian Marine Sciences Association, Darwin, Australia.

Johns, G.C. and Avise, J.C. (1998). A comparative summary of genetic distances in the vertebrates from the mitochondrial cytochrome $b$ gene. Molecular Biology and Evolution 15: 1481-1490.

Kelaart, E.F. (1858). Description of new and little known species of Ceylon nudibranchiate Mollusca and Zoophytes. Journal of the Royal Asiatic Society Ceylon Branch, Colombo 3: 84-139.

Kessing, B., Croom, H., Martin, A., McIntosh, C., McMillan, W.O. and Palumbi, S. (1989). The Simple Fool's Guide to PCR. University of Hawaii, Honolulu, Hawaii.

Mancini, G. and Sordi, M. (1965). Nuovo contributo alla conoscenza della cariologia dei gasteropodi opisthobranchi. Archivo Zoologica Italiano 50: 73-87.

Marcus, Ev. (1973). On the genus Bosellia (Mollusca; Gastropoda; Ascoglossa). Bulletin of Marine Science 23: 498-532.

Marcus, Ev. (1980). Review of western Atlantic Elysiidae (Opisthobranchia Ascoglossa) with a description of a new Elysia species. Bulletin of Marine Science 30: 54-79.

Marcus, Ev. (1982). Systematics of the genera of the order Ascoglossa (Gastropoda). Journal of Molluscan Studies Supplement 10: 1-31.

Medina, M. and Walsh, P.J. (2000). Molecular systematics of the order Anaspidea based on mitochondrial DNA sequences (12S, 16S, and CO1). Molecular Phylogenetics and Evolution 15: 41-58.

Mikkelsen, P.M. (1998). Cylindrobulla and Ascobulla in the western Atlantic (Gastropoda, Opisthobranchia, Sacoglossa): systematic review, description of a new species, and phylogenetic reanalysis. Zoologica Scripta 27: 49-71.

Pease, W.H. (1860). Descriptions of new species of Mollusca from the Sandwich Islands. Proceedings of the Zoological Society of London 1860: 18-38.

Pease, W.H. (1871). Descriptions of nudibranchiate Mollusca inhabiting Polynesia. American Journal of Conchology 6: 299-305.

Posada, D. and Crandall, K.A. (1998). MODELTEST: testing the model of DNA substitution. Bioinformatics 14: 817-818.

Sanders-Esser, B. (1984). Vergleichende Untersuchungen zur Anatomie und Histologie der vorderen Genitalorgane der Ascoglossa (Gastropoda, Euthyneura). Zoologische Jahrbucher (Anatomie) 111: 195-243.

Simon, C., Frati, F., Beckenbach, A., Crespi, B., Liu, H. and Flook, P. (1994). Evolution, weighting, and phylogenetic utility of mitochondrial gene sequences and a compilation of conserved polymerase chain reaction primers. Annals of the Entomological Society of America 87: 651-701.

Sokal, R.R. and Rohlf F.J. (1995). Biometry: The Principles and Practice of Statistics in Biological Research. $3^{\text {rd }}$ ed. W.H. Freeman, New York, New York.

Swofford, D.L. (1998). PAUP* 4.0: Phylogenetic Analysis Using Parsimony and Other Methods. Sinauer Associates, Sunderland, Massachusetts.

Thompson, T.E. (1973). Sacoglossan gastropod molluscs from eastern Australia. Proceedings of the Malacological Society of London 40: 239-251.

Thompson, T.E. (1977). Jamaican opisthobranch Molluscs I. Journal of Molluscan Studies 43: 93-140.

Thompson, T.E. and Jaklin, A. (1988). Eastern Mediterranean Opisthobranchia: Elysiidae (Sacoglossa $=$ Ascoglossa). Journal of Molluscan Studies 54: 59-69.

Wägele, H. (2004). Potential key characters in Opisthobranchia (Gastropoda, Mollusca) enhancing adaptive radiation. Organisms, Diversity and Evolution 4: 175-188.

Walsh, H.E., Metzger, D.A. and Higuchi, R. (1991). Chelix medium for simple extraction of DNA for PCR-based typing from forensic material. BioTechniques 10: 506513. 